\title{
Laser Performance of Neodymium- and Erbium-Doped GYSGG Crystals
}

\author{
Kai Zhong ${ }^{1,2}$ \\ 1 Institute of Laser and Optoelectronics, School of Precision Instruments and Optoelectronics Engineering, \\ Tianjin University, Tianjin 300072, China; zhongkai1984@gmail.com \\ 2 Key Laboratory of Opto-Electronic Information Technology, Ministry of Education (Tianjin University), \\ Tianjin 300072, China
}

Received: 28 February 2019; Accepted: 20 April 2019; Published: 24 April 2019

\begin{abstract}
Garnet crystals possess many properties that are desirable in laser host materials, e.g., they are suitable for diode laser (LD) pumping, stable, hard, optically isotropic, and have good thermal conductivity, permitting laser operation at high average power levels. Recently, a new garnet material, GYSGG, was developed by replacing some of the yttrium ions $\left(\mathrm{Y}^{3+}\right)$ with gadolinium ions $\left(\mathrm{Gd}^{3+}\right)$ in YSGG, demonstrating great potential as a laser host material. GYSGG crystals doped with trivalent neodymium ion $\left(\mathrm{Nd}^{3+}\right)$ and erbium ions $\left(\mathrm{Er}^{3+}\right)$ were successfully grown for laser generation in the near- and mid-infrared range, with some of the laser performances reaching the level of mature laser gain media. This paper gives an overview of the achievements made in $\mathrm{Nd}^{3+}-$ and $\mathrm{Er}^{3+}$-doped GYSGG lasers at different wavelength ranges. Additionally, full descriptions on Q-switching, mode-locking and wavelength-selecting methods for Nd:GYSGG, and the mechanisms of power scaling by co-doping sensitizers and deactivators in Er:GYSGG, are given. It is expected that this review will help researchers from related areas to quickly gain an understanding of these laser materials and promotes their commercialization and applications.
\end{abstract}

Keywords: Nd:GYSGG; Er:GYSGG; garnet laser crystal; solid-state laser; diode pumping; laser performance; radiation resistant

\section{Introduction}

Garnet crystals doped with the trivalent neodymium ion $\left(\mathrm{Nd}^{3+}\right)$ are regarded as the best solid-state laser materials, due to their good physical characteristics and laser performance, as well as the convenience of diode laser (LD) pumping around $808 \mathrm{~nm}$. Nd:YAG, Nd:GGG, Nd:GSGG and $\mathrm{Nd}$ :YSGG are several representatives [1-3]. From the view of industrialization, Nd:YAG is the most famous and successful type of $\mathrm{Nd}^{3+}$ doped garnet crystal to date in almost all application areas such as laser machining, display, medicine, scientific research, and military. Recently, however, a new garnet material, Nd:GYSGG, has been developed by replacing some of the yttrium ions $\left(\mathrm{Y}^{3+}\right)$ with gadolinium ions $\left(\mathrm{Gd}^{3+}\right)$ in Nd:YSGG. The material was successfully grown in the Anhui Institute of Optics and Fine Mechanics, Chinese Academy of Sciences [4-6]. The effective segregation coefficient of $\mathrm{Nd}^{3+}$ in GYSGG is much larger than that in YAG, and thus high-quality Nd:GYSGG bulk crystals with high doping concentration are much easier to grow than those of Nd:YAG using the conventional Czochralski method. Nd:GYSGG crystals with a diameter larger than $120 \mathrm{~mm}$ have been produced. The physicochemical and spectroscopic properties of Nd:GYSGG indicate prospective high-power laser operation. A comparison of the main physical and optical properties of Nd:YAG and Nd:GYSGG with doping concentration around 1.1 at $\%$ is given in Table 1. 
Table 1. Comparison of main physical and optical properties of Nd:YAG and Nd:GYSGG [4-7].

\begin{tabular}{ccc}
\hline Property & Nd:YAG & Nd:GYSGG \\
\hline Effective segregation coefficient of $\mathrm{Nd}^{3+}$ & $0.1-0.2$ & 0.598 \\
Mohs hardness & 8.5 & 6.55 \\
Density $\left(\mathrm{g} / \mathrm{cm}^{3}\right)$ & 4.56 & 5.62 \\
Thermal conductivity $\left(\mathrm{Wcm}^{-1} \mathrm{~K}^{-1}\right)$ & 14 & 4.33 \\
Refractive index at $1.0 \mu \mathrm{m}$ & 1.82 & 1.96 \\
Absorption bandwidth around $808 \mathrm{~nm}(\mathrm{~nm})$ & $2-3$ & 7 \\
Absorption coefficient around $808 \mathrm{~nm}\left(\mathrm{~cm}^{-1}\right)$ & $3-8$ & 4.9 \\
Fluorescence lifetime $(\mu \mathrm{s})$ & 230 & 221 \\
Emission linewidth $(\mathrm{nm})$ around $1.06 \mu \mathrm{m}$ & 0.45 & 4.95 \\
Stimulated emission cross-section for ${ }^{4} \mathrm{~F}_{3 / 2} \rightarrow{ }^{4} \mathrm{I}_{11 / 2}$ transition $\left(10^{-19} \mathrm{~cm}^{2}\right)$ & 2.8 & 1.5 \\
\hline
\end{tabular}

Besides the attractive properties of Nd:GYSGG for laser operation, experimental results also show that it has good radiation resistance [5], making it promising in applications in environments with ionizing radiation. Great attention has been paid to the laser performance of this material during the past decade. Continuous-wave (CW), Q-switched and mode-locked Nd:GYSGG lasers emitting wavelengths around $1.06 \mu \mathrm{m}$ and $1.1 \mu \mathrm{m}$ from the ${ }^{4} \mathrm{~F}_{3 / 2} \rightarrow{ }^{4} \mathrm{I}_{11 / 2}$ transition have been developed to achieve high-power operation. The ${ }^{4} \mathrm{~F}_{3 / 2} \rightarrow{ }^{4} \mathrm{I}_{13 / 2}$ transition enabling $1.3 \mu \mathrm{m}$ and $1.4 \mu \mathrm{m}$ lasers and the ${ }^{4} \mathrm{~F}_{3 / 2} \rightarrow{ }^{4} \mathrm{I}_{9 / 2}$ transition enabling $0.9 \mu \mathrm{m}$ lasers, have also been investigated. Due to the energy-level Stark splitting in the disordered Nd:GYSGG crystal, multiple laser wavelengths can be generated individually or simultaneously. Efficient nonlinear frequency conversion using Nd:GYSGG lasers as the fundamental wave to pump optical parametric oscillators (OPOs), and Raman lasers operating in the 1.5-1.6 $\mu \mathrm{m}$ eye-safe range, have been realized.

On the other hand, trivalent erbium ion $\left(\mathrm{Er}^{3+}\right)$-doped garnet crystals, such as Er:YAG and Er:YSGG, can directly give $2.7-3 \mu \mathrm{m}$ mid-infrared laser radiation through the ${ }^{4} \mathrm{I}_{11 / 2} \rightarrow{ }^{4} \mathrm{I}_{13 / 2}$ transition [4]. Such radiation has great value in medicine, as this is the strongest water absorption band throughout the optical regime. For the same purpose, and following a similar approach to Nd:GYSGG, another new category of laser materials - the Er:GYSGG crystals—have been grown by the Czochralski method. These crystals possess the main physical and anti-radiation merits of Nd:GYSGG [8]. Different ions can be used as sensitizers and deactivators to enhance the LD-to-laser conversion efficiency and overcome the self-terminating "bottleneck" effect. As a result, efficient mid-infrared laser generation has been obtained by pumping with LDs around $970 \mathrm{~nm}$.

Several as-grown crystal photographs of $\mathrm{Nd}^{3+}$ and $\mathrm{Er}^{3+}$ doped GYSGG crystals are shown in Figure 1. The details of the crystal growth (synthesis, single-crystal growth, doping concentration, segregation coefficient, etc.), physical properties (density, lattice parameter, refractive index, thermal conductivity, etc.), mechanical properties (hardness, fracture toughness, brittleness index, yield strength, etc.), spectral properties (absorption and emission spectrum, Judd-Ofelt analysis, energy-level transition, fluorescence lifetime, stimulated cross-section, etc.) and the radiation resistance of the Nd:GYSGG crystals have been studied comprehensively in previous works [5-7]. Some other important characteristics of Nd:GYSGG, such as the dependence of the fluorescence lifetime and non-radiative decay rate on the $\mathrm{Nd}^{3+}$ concentration, the dependence of the refractive index, nonlinear refractive index, elastic constants, and the thermal stress resistance on temperature, are still waiting for further research. The properties of Er:GYSGG crystals and sensitizer/deactivator-doped Er:GYSGG crystals are not as fully investigated as Nd:GYSGG, although some feedback on the crystal growth and main spectral properties (absorption and emission spectra, energy transfer diagram, etc.) is available in several works published in the past few years [8-11]. 


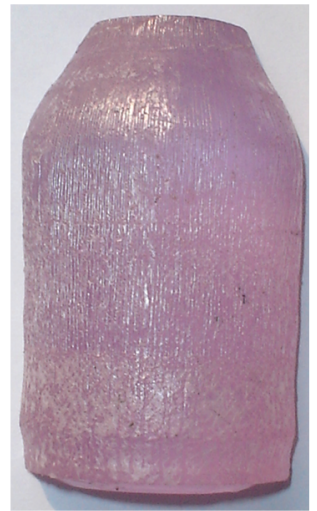

(a)

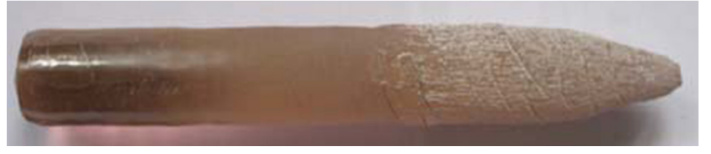

(b)

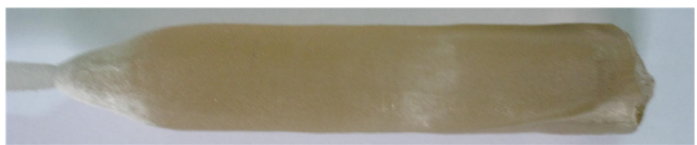

(c)

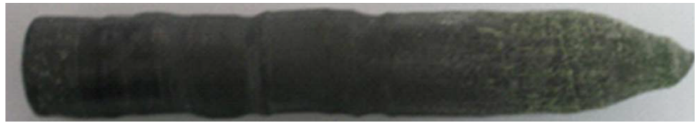

(d)

Figure 1. Photographs of as-grown $\mathrm{Nd}^{3+}$ - and $\mathrm{Er}^{3+}$-doped GYSGG crystals: (a) Nd:GYSGG [5]; (b) Er:GYSGG [8]; (c) Er,Pr:GYSGG [9]; (d) Cr,Er,Pr:GYSGG [10].

Considering the maturity of the aforementioned crystals, the related data integrity, as well as the orientation of this paper, this review is focused on the performance of $\mathrm{Nd}^{3+}$ - and $\mathrm{Er}^{3+}$-doped GYSGG lasers, and which is different from the representative review paper concentrating on the characterization of Nd:GSGG crystals [12]. This paper summarizes the development of $\mathrm{Nd}^{3+}-$ and $\mathrm{Er}^{3+}$-doped GYSGG lasers at different wavelengths under various operations. The basics and methods for improving the laser performance are also demonstrated and discussed. A comparison of main performance indicators with the common garnet materials indicates that $\mathrm{Nd}^{3+}$ and $\mathrm{Er}^{3+}$ doped GYSGG crystals are good candidates for solid-state laser media for efficient high-power laser operation at several wavelength ranges. It is expected that this review will help researchers from related areas to learn about this material and promote its commercialization and application, including applications in space and environments with ionizing radiation.

\section{Laser Performance of $\mathrm{Nd}^{3+}$-Doped GYSGG}

The absorption spectrum of Nd:GYSGG was measured by a Perkin Elmer Lambda 900 ultraviolet-visible-near infrared (UV/VIS/NIR) Spectrometer (PerkinElmer, Inc., Waltham, MA, USA), as shown in Figure 2a. There are eight absorption bands in the 400-1000 nm range originated from the ground state ${ }^{4} \mathrm{~F}_{9 / 2}$ and the peak is located at $808 \mathrm{~nm}$. The Judd-Ofelt method for the calculation of oscillation strength, as well as the estimation of spectrum parameters for the radiative transitions (fluorescence branching ratio, transition rate and lifetime) are given in [6]. The stimulated emission cross-section was obtained by the Füchtbauer-Ladenburg (F-L) equation based on the fluorescence parameters [13], as shown in Figure 2(b). Five potential major laser emission bands can be acquired located around $0.94 \mu \mathrm{m}\left({ }^{4} \mathrm{~F}_{3 / 2} \rightarrow{ }^{4} \mathrm{I}_{9 / 2}\right), 1.06 \mu \mathrm{m}\left({ }^{4} \mathrm{~F}_{3 / 2} \rightarrow{ }^{4} \mathrm{I}_{11 / 2}\right), 1.1 \mu \mathrm{m}\left({ }^{4} \mathrm{~F}_{3 / 2} \rightarrow{ }^{4} \mathrm{I}_{11 / 2}\right), 1.32 \mu \mathrm{m}$ $\left({ }^{4} \mathrm{~F}_{3 / 2} \rightarrow{ }^{4} \mathrm{I}_{13 / 2}\right)$, and $1.42 \mu \mathrm{m}\left({ }^{4} \mathrm{~F}_{3 / 2} \rightarrow{ }^{4} \mathrm{I}_{13 / 2}\right)$. Similar to other $\mathrm{Nd}^{3+}$-doped lasers, the gain at around $1.06 \mu \mathrm{m}$ is the strongest. The stimulated emission cross-section of the ${ }^{4} \mathrm{~F}_{3 / 2} \rightarrow{ }^{4} \mathrm{I}_{11 / 2}$ transition at $1.06 \mu \mathrm{m}$ was found to be $1.5 \times 10^{-19} \mathrm{~cm}^{2}$, which was also verified using both the laser efficiency comparison method and the threshold formula method [14]. 

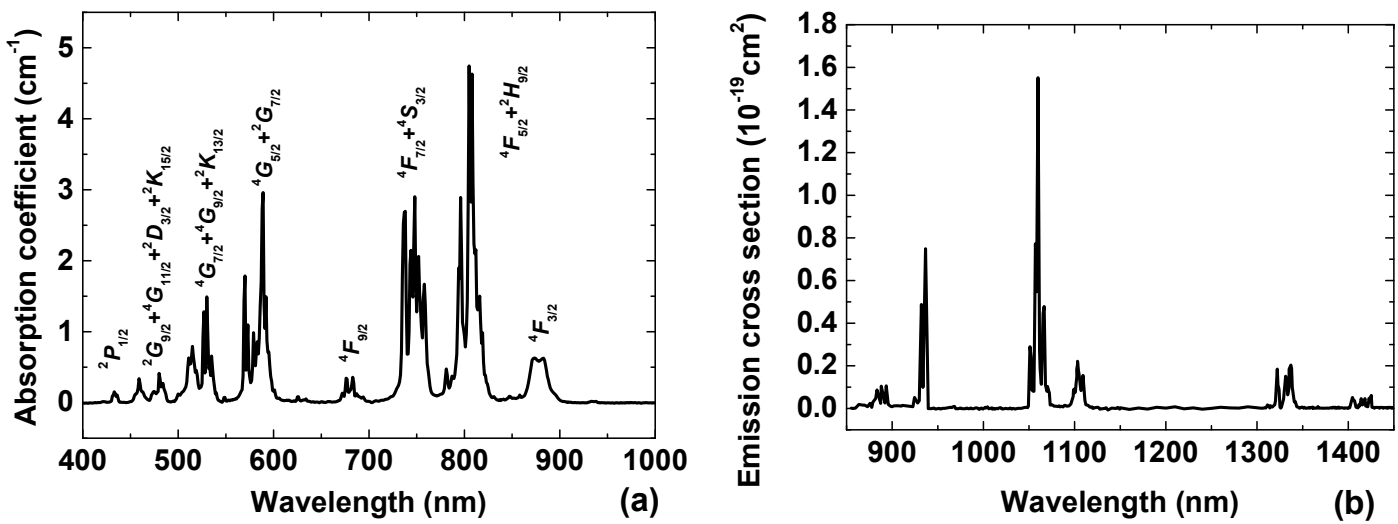

Figure 2. The room-temperature absorption coefficient $(400-1000 \mathrm{~nm})$ and stimulated emission cross-section (850-1450 $\mathrm{nm}$ ) of a 1.1 at\% doped Nd:GYSGG crystal [5].

\subsection{Nd:GYSGG Laser Operating in the 1.05-1.11 $\mu \mathrm{m}$ Range}

The feasible laser wavelengths from the ${ }^{4} \mathrm{~F}_{3 / 2} \rightarrow{ }^{4} \mathrm{I}_{11 / 2}$ transition are spread over a large range from 1.05 to $1.11 \mu \mathrm{m}$. Details of the energy levels are shown in Figure 3. The oscillation peak is located at around $1.06 \mu \mathrm{m}$, where two lines, at $1058 \mathrm{~nm}$ and $1062 \mathrm{~nm}$, possess comparable emission cross sections.

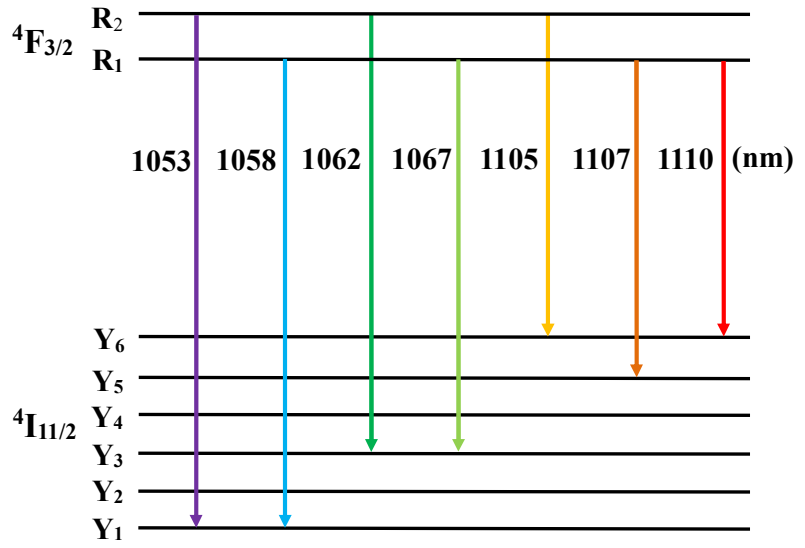

Figure 3. Energy-level transitions of ${ }^{4} \mathrm{~F}_{3 / 2} \rightarrow{ }^{4} \mathrm{I}_{11 / 2}$ excited at $808 \mathrm{~nm}$ for Nd:GYSGG.

The first demonstration of an Nd:GYSGG laser was in 2011 [15]. Using a typical linear diode-end-pumping cavity, as shown in Figure 4, stable CW dual-wavelength laser operation at 1058.4 and $1061.5 \mathrm{~nm}$ was achieved with a 1.1 at\% doped Nd:GYSGG crystal. The maximum output power was $10.1 \mathrm{~W}$, corresponding to a slope efficiency of nearly $60 \%$, which was among the best laser performances with mature garnet laser crystals like Nd:YAG. Using an acousto-optic (AO) Q-switch, the maximum single-pulse energy and peak power of the Nd:GYSGG laser reached $277 \mu \mathrm{J}$ and $4.6 \mathrm{~kW}$, respectively, with a pulse width around $60 \mathrm{~ns}$. Such a dual-wavelength pulsed laser could be used in terahertz generation through the nonlinear optical difference frequency generation (DFG) method.

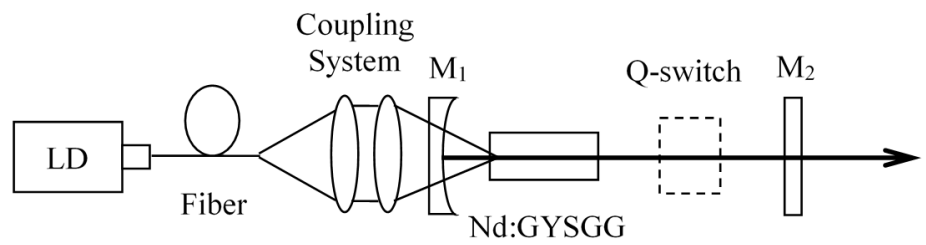

Figure 4. Experimental scheme of the diode-end-pumped Nd:GYSGG laser. LD: diode laser. 
In order to compress laser pulse width and enhance peak power, passively Q-switched Nd:GYSGG lasers have been extensively studied with various saturable absorbers. Benefiting from a much shorter cavity than in active Q-switching, Zhang et al. obtained short pulses, down to $6.6 \mathrm{~ns}$, using a Cr:YAG saturable absorber, and a peak power of up to $9.97 \mathrm{~kW}$ [16]. Since then, graphene oxide [17], tungsten disulfide $\left(\mathrm{WS}_{2}\right)$ [18], 2D-material $\left(\mathrm{SnSe}_{2}\right)$ [19], gold nano-triangles [20], and $\mathrm{TiS}_{2}, \mathrm{MoS}_{2}$, and $\mathrm{WS}_{2} / \mathrm{Sb}_{2} \mathrm{Te}_{3}$ mixed nanosheets [21] have been investigated for use in passive Q-switching. However, the poor physical and optical properties of these premature materials have severely limited their performance for loss modulation in the Nd:GYSGG laser cavity. Song et al. also observed dual-wavelength self-Q-switching in Nd:GYSGG [22], which might be caused by the nonlinear loss induced by the time-dependent thermal lensing effect in the laser crystal.

As the emission bandwidth of Nd:GYSGG is much broader than that of Nd:YAG, Nd:GYSGG has distinct advantages in generating ultrashort laser pulses. Zhang et al. realized CW mode-locked Nd:GYSGG laser operation at $1061.5 \mathrm{~nm}$ using a semiconductor saturable absorber mirror (SESAM) by employing an experimental scheme as shown in Figure 5 [23]. The maximum average output power reached $1.27 \mathrm{~W}$, corresponding to a slope efficiency of $18.9 \%$. At a repetition rate of $42 \mathrm{MHz}$, the pulse width was $3.1 \mathrm{ps}$, which is much shorter than that of a typical mode-locked Nd:YAG laser, thus fully exhibiting the excellent laser performance of Nd:GYSGG for mode-locked operation. Song et al. employed graphene oxide as the saturable absorber, achieving a passively Q-switched mode-locked Nd:GYSGG laser with two output wavelengths at 1057 and $1060 \mathrm{~nm}$. The pulse duration was $441 \mathrm{ps}$ at a repetition rate of $100 \mathrm{MHz}$ [24].

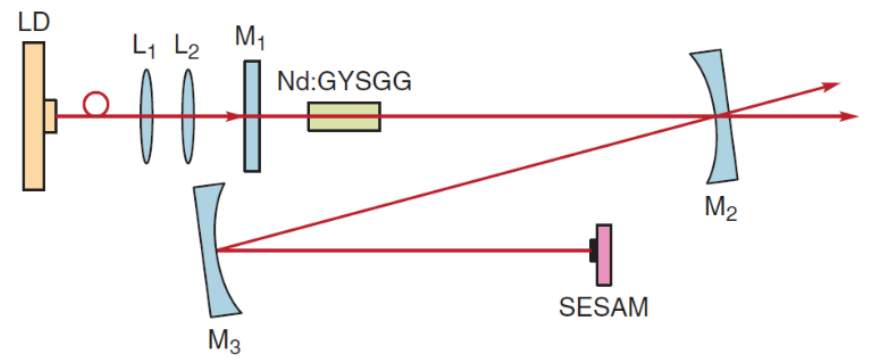

Figure 5. Schematic diagram of a mode-locking Nd:GYSGG laser [23]. SESAM: semiconductor saturable absorber mirror.

Benefiting from the diversity of upper and lower energy-level Stark splitting, laser transitions that are impossible with common garnet laser crystals can be realized with disordered Nd:GYSGG crystals. An example of this is the $1053 \mathrm{~nm}$ laser line which is close to the $\sigma$-polarized wavelength generated in Nd:YLF. Although the stimulated emission cross-section was much smaller ( $1 / 5$ of that at $1061.5 \mathrm{~nm}$ ), it was possible to achieve pure CW $1053 \mathrm{~nm}$ laser generation in Nd:GYSGG by optimizing the cavity mirror coatings to suppress the oscillation at 1058.4 and $1061.5 \mathrm{~nm}$ [25]. The maximum output power was $4.17 \mathrm{~W}$ and the optical-optical conversion efficiency reached $33.9 \%$. For passive Q-switching with a Cr:YAG absorber, the gain at $1058.4 \mathrm{~nm}$ was high enough to overcome its high loss, leading to stable dual-wavelength oscillation at 1052.8 and $1058.4 \mathrm{~nm}$. The single-pulse energy was up to $172.1 \mu \mathrm{J}$ with the peak power of $26.1 \mathrm{~kW}$, when the pulse width was $6.6 \mathrm{~ns}$ at $4.3 \mathrm{kHz}$. Such a Q-switched dual-wavelength laser with high peak power provides a good pump source to generate terahertz waves at $1.53 \mathrm{THz}$ via the nonlinear DFG process.

As shown in Figure $2 b$, an obvious emission band of Nd:GYSGG is located around $1.1 \mu \mathrm{m}$, which also comes from the ${ }^{4} \mathrm{~F}_{3 / 2} \rightarrow{ }^{4} \mathrm{I}_{11 / 2}$ transition. The precondition for high-power laser operation in this band is that the high gain around $1.06 \mu \mathrm{m}$ should be effectively restrained. Shen et al. reported the first demonstration of an Nd:GYSGG laser operating at $1104 \mathrm{~nm}$ with a $\mathrm{T}=6.6 \%$ output coupler, which delivered a CW laser output power of $4.7 \mathrm{~W}$, corresponding to a conversion efficiency of $24.6 \%$ and slope efficiency of $37 \%$ [26]. Using a high-Q cavity ( $\mathrm{T}=1.2-1.3 \%$ in the $1105-1110 \mathrm{~nm}$ range), Lin et al. realized simultaneous oscillation of three wavelengths at 1105, 1107, and $1110 \mathrm{~nm}$ [27]. 
Single-wavelength operation at $1110 \mathrm{~nm}$ reached $1.56 \mathrm{~W}$ with a $\mathrm{T}=4.5 \%$ output coupler [27]. According to the solution of rate equations for Q-switched solid-state lasers $[4,28,29]$, tremendous population inversion can be accumulated before the $Q$ switch opens, which produces much higher gain than the $\mathrm{CW}$ operation. Thus, in order to achieve Q-switched $1.1 \mu \mathrm{m}$ lasers, the cavity loss at $1.06 \mu \mathrm{m}$ should be sufficiently high to suppress its oscillation in Q-switching mode and the optimal coupling efficiency at $1.1 \mu \mathrm{m}$ should be higher than the CW operation. In a preliminary study, Dun et al. reported a passively Q-switched Nd:GYSGG laser at $1111.4 \mathrm{~nm}$ [30]. The saturable absorber was made of gold nanorods and the output couplers had transmissions of 5.7 and $9 \%$, which realized a maximum output power, pulse repetition rate, and pulse width of $125 \mathrm{~mW}, 120 \mathrm{kHz}$ and $550.6 \mathrm{~ns}$, respectively.

\subsection{Nd:GYSGG Laser Operating in the 1.3-1.45 $\mu$ m Range}

Referring to Figure $2 b$, there are two separated parts from the ${ }^{4} \mathrm{~F}_{3 / 2} \rightarrow{ }^{4} \mathrm{I}_{13 / 2}$ transition一one is in the 1.3-1.35 $\mu \mathrm{m}$ range and the other is in the 1.4-1.43 $\mu \mathrm{m}$ range, with possible emission wavelengths shown in Figure 6. Apparently, the stimulated emission cross-section for the 1.3-1.35 $\mu \mathrm{m}$ range is much higher, where the peak is located at $1336 \mathrm{~nm}$. However, to achieve the $1.4 \mu \mathrm{m}$ laser operation, stringent requirements should be fulfilled, such as a high-finesse cavity and good suppression of the $1.3 \mu \mathrm{m}$ laser oscillation.

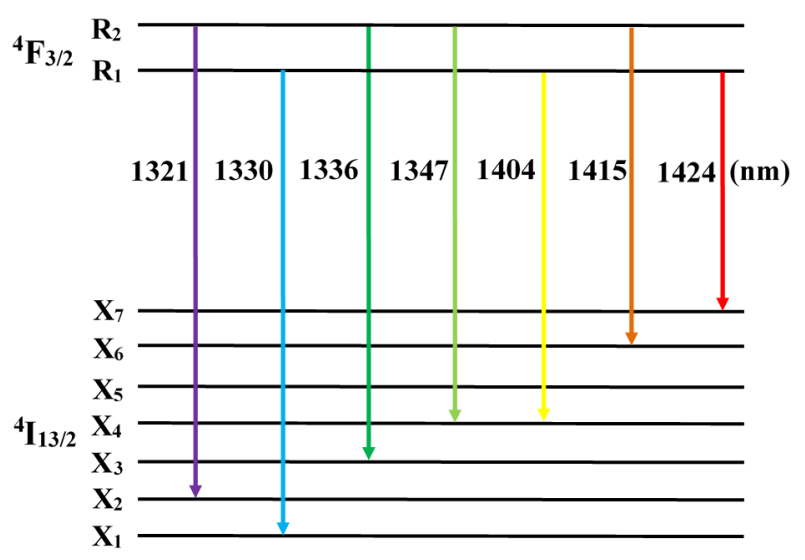

Figure 6. Energy-level transitions of ${ }^{4} \mathrm{~F}_{3 / 2} \rightarrow{ }^{4} \mathrm{I}_{13 / 2}$ excited at $808 \mathrm{~nm}$ for Nd:GYSGG.

The first Nd:GYSGG laser in the 1.3-1.35 $\mu$ m wavelength range was reported in 2012 [31]. Using a diode-end-pumped plane-parallel cavity with different out-coupling efficiencies of 8.4 and $6.0 \%$, single-wavelength operation at $1336 \mathrm{~nm}$ and dual-wavelength operation at 1321/1336 nm with a minor wavelength at $1330 \mathrm{~nm}$ were achieved with variable power proportions according to the pump intensity. The maximum output power at $1336 \mathrm{~nm}$ was $1.98 \mathrm{~W}$ with $13.5 \mathrm{~W}$ incident LD pump power, corresponding to a conversion efficiency of $14.7 \%$. Later, the laser cavity was optimized into a plano-concave one, and the maximum output power was increased to $2.5 \mathrm{~W}$ at $1336 \mathrm{~nm}$, corresponding to a conversion efficiency of $18.5 \%$ [32].

In order to achieve $1.4 \mu \mathrm{m}$ laser oscillation, the output coupler was designed to have high transmission loss ( $\mathrm{T}>60 \%$ ) in the $1.3-1.38 \mu \mathrm{m}$ range, and the $1.4 \mu \mathrm{m}$ cavity loss was minimized to accumulate sufficient gain. With an output coupler that had transmissions of $\mathrm{T}=1.9 \%$ and $\mathrm{T}=1.1 \%$ at $1404 \mathrm{~nm}$ and $1424 \mathrm{~nm}$, respectively, $250 \mathrm{~mW}$ output power was obtained when the absorbed pump power was $9.1 \mathrm{~W}$ [32]. The pump thresholds for both the $1404 \mathrm{~nm}$ and $1424 \mathrm{~nm}$ lasers were around $1 \mathrm{~W}$. The power of the $1424 \mathrm{~nm}$ laser grew faster while increasing the pump power, during which a quite weak $1415 \mathrm{~nm}$ laser line emerged. The transmissions of the second output coupler were $\mathrm{T}=7.9 \%$ at $1404 \mathrm{~nm}$ and $\mathrm{T}=4.3 \%$ at $1424 \mathrm{~nm}$, which successfully eliminated the oscillations at $1404 \mathrm{~nm}$ and $1415 \mathrm{~nm}$ and realized pure $1424 \mathrm{~nm}$ laser emission. The maximum power at $1424 \mathrm{~nm}$ reached $707 \mathrm{~mW}$ with a $10.4 \mathrm{~W}$ absorbed pump power, corresponding to a conversion efficiency of $6.8 \%$ and slope efficiency of $9.4 \%$. Since above $1.4 \mu \mathrm{m}$ the laser wavelength enters the "eye-safe" band, the 
$1.4 \mu \mathrm{m}$ Nd:GYSGG laser provides an option for lidar and range-finding applications, especially in environments with ionizing radiation.

Although AO Q-switching is a conventional and preferred approach for generating stable laser pulses, passive Q-switching is sometimes superior due to its narrower pulse width and higher peak power with a much shorter cavity. As an excellent candidate for saturable absorbers working in the 1.3-1.4 $\mu \mathrm{m}$ range, $\mathrm{V}^{3+}$ :YAG has good optical and physical properties. Its absorption cross-section for the ground state is $7.2 \times 10^{-18} \mathrm{~cm}^{2}$ at $1.34 \mu \mathrm{m}$, while it is much lower for the excited state, making it easy to be bleached. Song et al. reported a $1331 \mathrm{~nm} \mathrm{~V}^{3+}$ :YAG Q-switched Nd:GYSGG laser delivering an average power of $251 \mathrm{~mW}$ [33]. The minimum pulse width was $23.9 \mathrm{~ns}$ at $11 \mathrm{kHz}$, corresponding to a peak power of $954 \mathrm{~W}$. Lin et al. investigated another saturable absorber for passively Q-switching, $\mathrm{Co}: \mathrm{MgAl}_{2} \mathrm{O}_{4}$ [34], whose absorption peak was close to $1520 \mathrm{~nm}$ and which is mostly used for lasers in the eye-safe wavelength region. The $\mathrm{Co}: \mathrm{MgAl}_{2} \mathrm{O}_{4}$ Q-switched Nd:GYSGG laser at $1331 \mathrm{~nm}$ could give an output power of $225 \mathrm{~mW}$, with a pulse width of $20.5 \mathrm{~ns}$ and a peak power of $1.3 \mathrm{~kW}$.

A narrow-linewidth (sub-pm level) AO Q-switched Nd:GYSGG laser generating nanosecond pulses at $1336.6 \mathrm{~nm}$ was realized by Li et al. in a ring cavity [35], as shown in Figure 7. Using a birefringent filter and two etalons with different thicknesses for wavelength selection and linewidth compression, a linewidth of $0.85 \mathrm{pm}$ was achieved with a macropulse output energy of $36.7 \mathrm{~mJ}$ at $10 \mathrm{~Hz}$. At a pulse repetition rate of $80 \mathrm{~Hz}$, the width of the micropulse was $300 \mathrm{~ns}$ and the peak power reached $15.3 \mathrm{~kW}$. The maximum output macropulse energy at $1336.0 \mathrm{~nm}$ reached $365 \mathrm{~mJ}$ when the LD pump pulse energy was $4.23 \mathrm{~J}$, with a pump threshold of $1.23 \mathrm{~J}$ and a conversion efficiency of $8.62 \%$. The $\mathrm{M}^{2}$ factors of the narrow-linewidth laser in both orthogonal directions were less than 1.5, indicating that it was a good Gaussian fundamental transverse mode. The wavelength stability was also kept at a good level, with a fluctuation of less than 2 pm for 20 minutes. Applications of such a narrow-linewidth laser in optical frequency standard through its eighth harmonics $(167.079 \mathrm{~nm})$ in the deep ultraviolet range were also proposed.

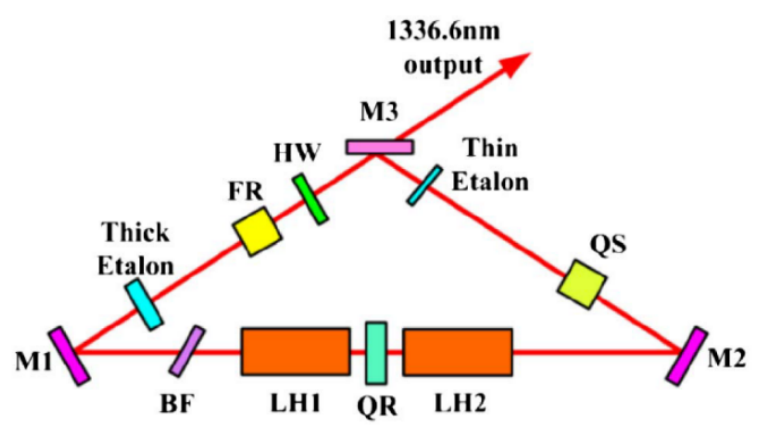

Figure 7. Experimental setup of the narrow-linewidth pulsed Nd:GYSGG ring laser at $1336 \mathrm{~nm}$ [35].

\subsection{Nd:GYSGG Laser Operating in the 0.9-0.95 $\mu \mathrm{m}$ Range}

The ${ }^{4} \mathrm{~F}_{3 / 2} \rightarrow{ }^{4} \mathrm{I}_{9 / 2}$ transition of $\mathrm{Nd}^{3+}$-doped lasers provides a straightforward method for high-brightness laser sources in the $0.9-0.95 \mu \mathrm{m}$ range, which are attractive in pumping $\mathrm{Yb}^{3+}$-doped laser gain media (e.g., Yb:YAG), water vapor absorption lidar, and the generation of blue laser through frequency doubling. However, as quasi-three-level systems, the power scaling in this range is usually limited. Besides taking measures to reduce reabsorption loss, a well-designed cavity is also necessary to achieve laser oscillation with high output power and efficiency. The emission cross-section of the ${ }^{4} \mathrm{~F}_{3 / 2} \rightarrow{ }^{4} \mathrm{I}_{9 / 2}$ transition in Nd:GYSGG is slightly lower than the ${ }^{4} \mathrm{~F}_{3 / 2} \rightarrow{ }^{4} \mathrm{I}_{11 / 2}$ transition around $1.06 \mu \mathrm{m}$, making it a good candidate for $0.9 \mu \mathrm{m}$ lasers, as shown in Figure $2 \mathrm{~b}$. Two distinct peaks are located in this range, one at $933 \mathrm{~nm}$ and the other at $937 \mathrm{~nm}$. The weaker former transition was from R2 to Z5 and the stronger latter one was from R1 to Z5, with both fluorescence linewidths being around $1.6 \mathrm{~nm}$.

The first quasi-three-level Nd:GYSGG laser was reported in 2013 [36]. With a 1.1 at $\%$ doped Nd:GYSGG crystal, the CW output power at $937 \mathrm{~nm}$ was $0.8 \mathrm{~W}$ using a simple plano-concave cavity 
at $0{ }^{\circ} \mathrm{C}$ working temperature. The conversion efficiency and slope efficiency reached $9.8 \%$ and $15.3 \%$, respectively. Significant power reduction and threshold increase was observed if the working temperature was increased, due to the serious reabsorption loss in the Nd:GYSGG crystal. In order to improve the output power, crystals that are longer and have a lower doping concentration should be favorable, since they can greatly alleviate the reabsorption and thermal effects inside the laser crystal. Other potential improvements are better cavity arrangement, mirror and crystal coatings, etc. Unfortunately, there have been few publications on the quasi-three-level Nd:GYSGG laser since 2013. Considering its large stimulated emission cross-section at $0.94 \mu \mathrm{m}$, high-power laser emission comparable to that with Nd:YAG in this band can be expected under optimal crystal growth and cavity design [37].

Cryogenic cooling has been extensively studied for scaling the power of quasi-three-level $\mathrm{Yb}^{3+}$, $\mathrm{Ho}^{3+}$-, and $\mathrm{Nd}^{3+}$-doped YAG lasers [38-40], demonstrating prominent benefits in reducing reabsorption loss, increasing emission cross-section, and improving the thermo-optical properties of the gain media. Recent results show that monolithic Nd:YAG lasers can deliver an output power of over $30 \mathrm{~W}$ at $946 \mathrm{~nm}$ under cryogenic cooling, corresponding to a slope efficiency of up to 78\% [41], which provides an efficient method for scaling the power of a $937 \mathrm{~nm}$ Nd:GYSGG laser. On the other hand, the fact that the quasi-three-level laser performance in the $0.9-0.95 \mu \mathrm{m}$ range is sensitive to working temperature can be effectively utilized. In a multiple-wavelength laser containing a laser line from the ${ }^{4} \mathrm{~F}_{3 / 2} \rightarrow{ }^{4} \mathrm{I}_{9 / 2}$ transition (quasi-three-level system), if its oscillation is restrained the lasing at the other wavelengths (four-level systems) should be enhanced. This is due to the fact that all the laser wavelengths share the same upper level, and once the $0.9 \mu \mathrm{m}$ laser is reabsorbed the population inversion is accumulated, bringing extra gain at the other wavelengths. Such a concept prompted a novel idea for power-ratio tunable dual/multiple-wavelength lasers via the adjustment of the working temperature. A successful implementation was demonstrated through a dual-band Nd:GYSGG laser at $0.94 \mu \mathrm{m}$ and $1.06 \mu \mathrm{m}$ [42]. As shown in Figure 8, the power ratio of the two bands could be stably and repeatably tuned at a large scale: the power proportion at $1.06 \mu \mathrm{m}$ was tuned from 12.4 to $100 \%$ while the working temperature was increased from 2 to $20^{\circ} \mathrm{C}$ under an incident pump power of $3.14 \mathrm{~W}$.

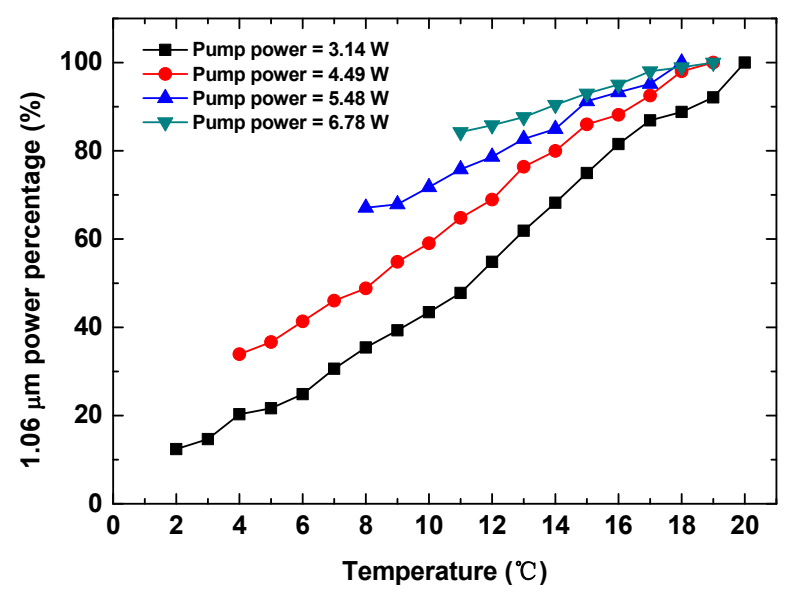

Figure 8. Tunable $1.06 \mu \mathrm{m}$ power ratio in a dual-band $(0.94 \mu \mathrm{m}$ and $1.06 \mu \mathrm{m}) \mathrm{Nd}$ :GYSGG laser achieved via changing the working temperature [42].

\subsection{Nd:GYSGG Laser Performance: Summary}

To summarize, the Nd:GYSGG laser performance at major oscillating wavelengths is shown in Table 2, with operation modes covering CW, Q-switched, and mode-locked. All the pump sources are LDs at $808 \mathrm{~nm}$, and the average output power, single-pulse energy, and optical-optical conversion efficiency from LD to laser output are given in Table 2. Although the average output power and pulse energy are not as remarkable as those of Nd:YAG lasers, the maximum optical-optical conversion efficiency can reach around $55 \%$, which is relatively impressive for diode-end-pumped solid-state lasers. 
It should be noted that there are still serious barriers to improving the performance of Nd:GYSGG lasers, e.g., the lack of accurate modeling of rate equations to acquire the dynamics of population inversion and laser generation, and the lack of intensive analysis of the dominant energy transfer mechanisms. Under this premise, the doping concentration of Nd:GYSGG crystals can be optimized and better cavity design is straightforward, paving the way for high-power and efficient Nd:GYSGG lasers, especially for quasi-three-level laser systems. Further power and energy scaling can incorporate side-pumping or slab lasers, which allow a much higher incident pump power; however, these schemes have not yet been fully exploited. In particular, a much larger emission linewidth $(4.95 \mathrm{~nm})$ of Nd:GYSGG over Nd:YAG $(0.45 \mathrm{~nm})$, etc., has demonstrated great potential in ultrashort pulse generation. A concise comparison of the pulse durations for Nd:GYSGG and commonly used laser crystals for diode-end-pumped mode-locked lasers around $1.06 \mu \mathrm{m}$ (which were all achieved with SESAMs) is given in Table 3.

Table 2. Laser performance at major oscillating wavelengths of Nd:GYSGG.

\begin{tabular}{cccccc}
\hline Wavelength (nm) & Operation Mode & Pumping Scheme & Power/Energy & Efficiency & $\mathbf{M}^{\mathbf{2}}$ Factor \\
\hline $937[36]$ & $\mathrm{CW}$ & End & $0.8 \mathrm{~W}$ & $9.8 \%$ & - \\
$1053[25]$ & $\mathrm{CW}$ & End & $4.17 \mathrm{~W}$ & $33.9 \%$ & 13 \\
$1053 / 1058[25]$ & Q-switched & End & $0.74 \mathrm{~W} / 172 \mu \mathrm{J}$ & $16.1 \%$ & - \\
$1058 / 1061[15]$ & $\mathrm{CW}$ & End & $10.1 \mathrm{~W}$ & $54.7 \%$ & 2.8 \\
$1058 / 1061[15]$ & Q-switched & End & $2.77 \mathrm{~W} / 277 \mu \mathrm{J}$ & $24.3 \%$ & - \\
$1061[23]$ & Mode-locked & End & $1.27 \mathrm{~W}$ & $17.2 \%$ & - \\
$1104[26]$ & CW & End & $4.7 \mathrm{~W}$ & $24.6 \%$ & - \\
$1110[27]$ & $\mathrm{CW}$ & End & $1.56 \mathrm{~W}$ & $14.1 \%$ & - \\
$1321 / 1336[32]$ & $\mathrm{CW}$ & End & $1.998 \mathrm{~W}$ & $12.9 \%$ & 1.2 \\
$1336[32]$ & $\mathrm{CW}$ & End & $2.5 \mathrm{~W}$ & $18.5 \%$ & - \\
$1336[35]$ & Q-switched & Side & $356 \mathrm{~mJ}$ & $8.6 \%$ & 1.4 \\
$1424[32]$ & CW & End & $0.707 \mathrm{~W}$ & $6.8 \%$ & - \\
\hline
\end{tabular}

Table 3. Comparison of emission linewidth and SESAM-mode-locked laser pulse duration around $1.06 \mu \mathrm{m}$ between Nd:GYSGG and commonly used laser gain media.

\begin{tabular}{ccccc}
\hline Property & Nd:YAG & Nd:YVO $_{4}$ & Nd:GdVO $_{4}$ & Nd:GYSGG \\
\hline $\begin{array}{c}\text { Emission linewidth (nm) } \\
\text { Mode-locked pulse } \\
\text { duration (ps) }\end{array}$ & $0.45[4]$ & $0.8[43]$ & $1.25[43]$ & $4.95[6]$ \\
\hline
\end{tabular}

\section{Laser Performance of $\mathrm{Er}^{3+}$-Doped GYSGG}

\subsection{Mid-Infrared Laser Performance of Er:GYSGG at $2.79 \mu \mathrm{m}$}

High-quality Er:GYSGG crystals and their laser performance were firstly reported by the Anhui Institute of Optics and Fine Mechanics, Chinese Academy of Sciences, in 2013 [8]. The Er:GYSGG crystals were grown by the Czochralski method by replacing some of the $\mathrm{Gd}^{3+}$ ions with $\mathrm{Y}^{3+}$ in Er:GSGG, realizing a crystal size of approximately $\varphi 25 \mathrm{~mm} \times 100 \mathrm{~mm}$. Excited by a $968 \mathrm{~nm} \mathrm{LD}$, the location of the strongest fluorescence peak was at $2796 \mathrm{~nm}$. The upper $\left({ }^{4} \mathrm{I}_{11 / 2}\right)$ and lower $\left({ }^{4} \mathrm{I}_{13 / 2}\right)$ energy levels had lifetimes of $1.2 \mathrm{~ms}$ and $3.9 \mathrm{~ms}$, respectively, indicating that the upper level life time was kept unchanged while the lower lifetime was significantly decreased during the ion exchange, which was favorable for improving the $2.7-3 \mu \mathrm{m}$ laser performance. The maximum output pulse energy was $2.43 \mathrm{~mJ}$ using a $968 \mathrm{~nm}$ quasi-CW LD as the pump source. The corresponding peak power was $1.25 \mathrm{~W}$ and the optical-optical conversion efficiency reached $6.7 \%$. The output laser spectrum ranged from 2.791 to $2.799 \mu \mathrm{m}$, where the center was at $2.796 \mu \mathrm{m}$ and the spectrum linewidth (FWHM) was $4.5 \mathrm{~nm}$. It was also found that strong gamma irradiation $(100 \mathrm{Mrad})$ introduced negligible variation in laser power/energy, conversion efficiency, and beam quality, proving the good potential of Er:GYSGG as a new mid-infrared radiation-resistant laser material. 


\subsection{Laser Performance of Er,Pr:GYSGG Using $\mathrm{Cr}^{3+}$ as the Deactivator}

An unavoidable problem for $\mathrm{Er}^{3+}$ doped laser gain media is the self-terminating effect for the ${ }^{4} \mathrm{I}_{11 / 2} \rightarrow{ }^{4} \mathrm{I}_{13 / 2}$ transition producing the $2.7-3 \mu \mathrm{m}$ mid-infrared wavelength, which essentially originates from the shorter lifetime of the upper laser level compared to the lower level. Besides high-doping-induced upconversion (UP) and cross-relaxation (CR), co-doping with deactivator ions is recognized as an effective method to alleviate the self-terminating effect by reducing the lifetime of the lower laser level. Chen et al. used trivalent praseodymium ions $\left(\mathrm{Pr}^{3+}\right)$ as the deactivator and successfully grew high-quality Er,Pr:GYSGG crystals with the Czochralski method [9]. The energy transfer (ET) diagram between $\mathrm{Er}^{3+}$ and $\mathrm{Pr}^{3+}$ ions is shown in Figure 9. As there is an energy level $\left({ }^{3} \mathrm{~F}_{4}\right)$ in $\mathrm{Pr}^{3+}$ that is adjacent to the ${ }^{4} \mathrm{I}_{13 / 2}$ level of $\mathrm{Er}^{3+}$, co-doping with $\operatorname{Pr}^{3+}$ deactivated the terminal laser level. A few advantages, such as allowing laser operation at lower $\mathrm{Er}^{3+}$ ion doping level to reduce loss and ${ }^{4} \mathrm{I}_{11 / 2}$ upconversion, and simplifying the dynamics through quasi-four-level operation, are provided through this process. The actual $\mathrm{Er}^{3+} \rightarrow \mathrm{Pr}^{3+}$ energy transfer efficiencies were $56.7 \%$ and $84.6 \%$ in $\mathrm{ET}_{1}$ and $\mathrm{ET}_{2}$, respectively. The upper level $\left({ }^{4} \mathrm{I}_{11 / 2}\right)$ and lower level $\left({ }^{4} \mathrm{I}_{13 / 2}\right)$ had lifetimes of 0.52 and $0.60 \mathrm{~ms}$, respectively, resulting from the doping with $\mathrm{Pr}^{3+}$ ions. A maximum $\mathrm{CW}$ output power of $284 \mathrm{~mW}$ was produced from the Er,Pr:GYSGG laser with a slope efficiency of $17.4 \%$. Pulses with a width of $0.5 \mathrm{~ms}$ and a repetition rate of $50 \mathrm{~Hz}$ were also generated in pulsed mode, with a maximum laser energy, peak power and slope efficiency of $2.4 \mathrm{~mJ}, 4.8 \mathrm{~W}$, and $18.3 \%$, respectively. By using a composite GYSGG/Er,Pr:GYSGG crystal to alleviate the thermal effects and optimizing the doping concentration of $\mathrm{Er}^{3+}$ and $\mathrm{Pr}^{3+}$ ions, the maximum $\mathrm{CW}$ output power was increased to $825 \mathrm{~mW}$ and single-pulse energy reached $3.65 \mathrm{~mJ}$, corresponding to slope efficiencies of $19.2 \%$ and $22.7 \%$, respectively [47]. Recently, Zhao et al. adopted the diode side-pumping scheme to pump Er,Pr:GYSGG, and realized a maximum output power of $8.66 \mathrm{~W}$ with a slope efficiency of $14.8 \%$ at a repetition rate of $125 \mathrm{~Hz}$ and pulse width of $200 \mu \mathrm{s}$. These impressive results indicate that Er,Pr:GYSGG crystals have great potential in high-power $2.79 \mu \mathrm{m}$ laser generation by deactivation and LD side-pumping [48].

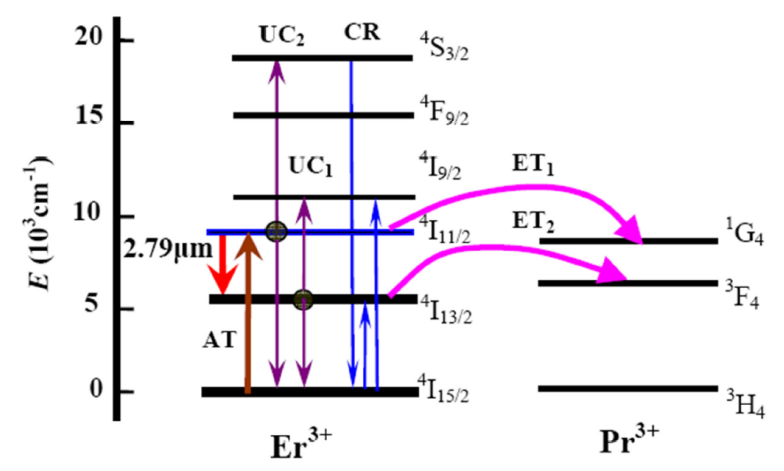

Figure 9. Energy transfer diagram between $\mathrm{Er}^{3+}$ and $\mathrm{Pr}^{3+}$ ions in Er,Pr:GYSGG [9].

\subsection{Laser Performance of $C r, E r, P r: G Y S G G$ with a Wide Absorption Band for Lamp Pumping}

Trivalent chromium ions $\left(\mathrm{Cr}^{3+}\right)$ can be used as a sensitizer in Er,Pr:GYSGG, making it possess extra wide absorption bands in the visible range, as shown in Figure 10. This property is crucial for improving the laser performance using flash-lamp pumping with a broad emission spectrum [10]. Luo et al. realized an output energy of $278 \mathrm{~mJ}$ at $2.79 \mu \mathrm{m}$ with a Cr,Er,Pr:GYSGG crystal and a flash lamp. Benefiting from the good absorption for the pump energy, the electrical-optical and slope efficiency reached $0.6 \%$ and $0.7 \%$, respectively. The maximum average output power was $2.9 \mathrm{~W}$ at a repetition rate of $60 \mathrm{~Hz}$. A GYSGG/Cr,Er,Pr:GYSGG composite crystal was also used to alleviate the thermal effects, with which the maximum pulse energy was increased to $342.8 \mathrm{~mJ}$ at $5 \mathrm{~Hz}$, corresponding to the electrical-optical and slope efficiencies of $0.86 \%$ and $1.08 \%$, respectively [49]. The laser emitted from a composite crystal was also found to have better beam quality, fully demonstrating its obvious advantage in reducing thermal effects and improving laser performance. 


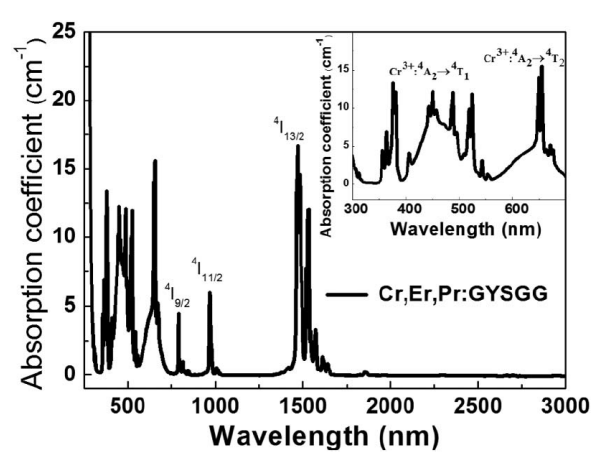

(a)

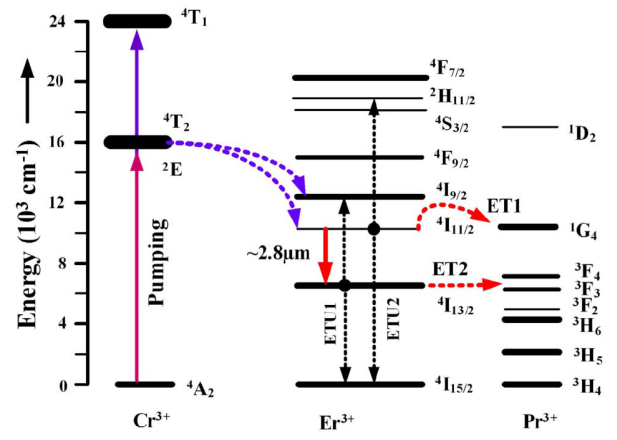

(b)

Figure 10. The impact of $\mathrm{Cr}^{3+}$-doping on Er,Pr:GYSGG: (a) absorption spectrum; (b) diagram of energy transfer among $\mathrm{Cr}^{3+}, \mathrm{Er}^{3+}$ and $\operatorname{Pr}^{3+}$ ions [10].

\subsection{Laser Performance of $Y b, E r, H o: G Y S G G$ Using $Y b^{3+}$ and $\mathrm{Ho}^{3+}$ as Sensitizer and Deactivator}

Another crystal in this category, $\mathrm{Yb}$,Er,Ho:GYSGG, in which trivalent ytterbium ion $\left(\mathrm{Yb}^{3+}\right)$ and trivalent holmium ion $\left(\mathrm{Ho}^{3+}\right)$ act as sensitizer and deactivator ions, respectively, also gives an approach to improve the $\mathrm{Er}^{3+}$ laser performance in the 2.7-3 $\mu \mathrm{m}$ range [11]. An energy transfer diagram among $\mathrm{Yb}^{3+}, \mathrm{Er}^{3+}$, and $\mathrm{Ho}^{3+}$ ions is shown in Figure 11. Since the ${ }^{5} \mathrm{I}_{7}$ level position of $\mathrm{Ho}^{3+}$ is close to the lower level, ${ }^{4} \mathrm{I}_{13 / 2}$, of $\mathrm{Er}^{3+}$, depopulation occurs at ${ }^{4} \mathrm{I}_{13 / 2}$ by a resonant energy transfer process; this significantly decreases the lifetime of the lower ${ }^{4} \mathrm{I}_{13 / 2}$ level (35\% decrease), and population inversion is much easier to achieve under lower pumping level. Under $967 \mathrm{~nm}$ LD pumping, the output power reached $411 \mathrm{~mW}$ at $2.79 \mu \mathrm{m}$ with a $\mathrm{Yb}, \mathrm{Er}, \mathrm{Ho}$ :GYSGG crystal, corresponding to optical-optical and slope efficiencies of $11.6 \%$ and $13.1 \%$, respectively. The laser threshold was significantly reduced to $81 \mathrm{~mW}$ as a result of the $\mathrm{Ho}^{3+}$ ion doping.

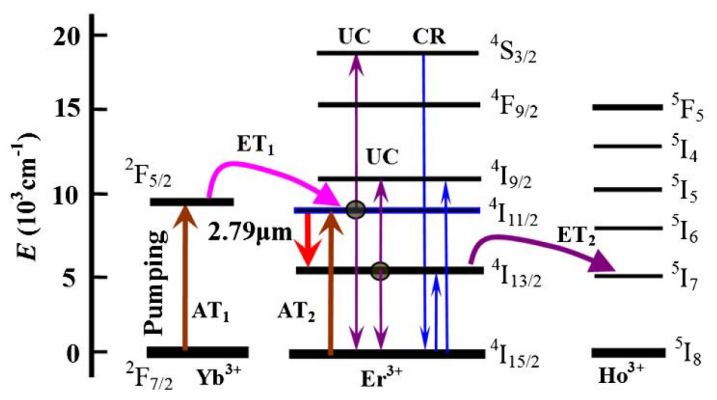

Figure 11. Energy transfer diagram among $\mathrm{Yb}^{3+}, \mathrm{Er}^{3+}$, and $\mathrm{Ho}^{3+}$ ions [11].

\subsection{Mid-Infrared Laser Performance of $\mathrm{Cr}, \mathrm{Yb}, \mathrm{Ho}, \mathrm{Pr}$ : GYSGG}

$\mathrm{Ho}^{3+}$-doped laser crystals where $\mathrm{Ho}^{3+}$ works as the active ion exhibit a broadband fluorescence spectrum in the 2.7-3 $\mu \mathrm{m}$ range, which benefits the realization of multiple-wavelength or ultrashort laser generation [50]. However, there are problems with such crystals, in that the absorption is very low for $\mathrm{Ho}^{3+}$ lasers pumped by LD and flash lamp, and the lower laser energy level ${ }^{5} \mathrm{I}_{7}$ has a much longer lifetime than that of the upper level ${ }^{5} \mathrm{I}_{6}$, making laser generation very difficult. Recently, Zhang et al. developed a new crystal $\mathrm{Cr}, \mathrm{Yb}, \mathrm{Ho}, \mathrm{Pr}$ : GYSGG, in which the $\mathrm{Cr}^{3+}$ and $\mathrm{Yb}^{3+}$ ions were used to sensitize the $\mathrm{Ho}^{3+}$ ions [51] and the $\mathrm{Pr}^{3+}$ ions acted as the deactivator to reduce the lifetime of the lower laser level $\left({ }^{5} \mathrm{I}_{7}\right)$. The average output power at $2.86 \mu \mathrm{m}$ reached $257 \mathrm{~mW}$ with flash-lamp pumping at $5 \mathrm{~Hz}$, corresponding to an electrical-optical efficiency of $0.033 \%$ and a slope efficiency of $0.04 \%$. As a new gain medium with radiation resistance, the $\mathrm{Cr}, \mathrm{Yb}, \mathrm{Ho}, \mathrm{Pr}$ :GYSGG crystal demonstrated the ability for laser emission in the mid-infrared range. However, its laser performance is still far below that of $\mathrm{Er}^{3+}$-doped lasers at present. 


\subsection{Mid-Infrared Laser Performance of Er ${ }^{3+}$-Doped GYSGG: Summary}

Table 4 summarizes the achieved laser performances of Er:GYSGG and sensitizer/deactivatordoped Er:GYSGG crystals. Most pump sources are LDs around $970 \mathrm{~nm}$, except the $\mathrm{Cr}^{3+}$-doped crystals, which possess wide absorption bands and are suitable for lamp pumping, as noted in the table. Both the overall conversion efficiency and maximum power/energy output are approaching the level of Er:YAG [52], Er:YLF [53], Er:YSGG [54], etc. Further research should focus on the Q-switching operation for high-peak-power output, as only free-running CW and pulsed $\mathrm{Er}^{3+}$-doped GYSGG lasers have been reported. Power scaling can also incorporate cryogenic cooling to improve the thermal, spectroscopic, and laser properties of the laser crystals [55].

Table 4. Laser performance of Er:GYSGG and sensitizer/deactivator-doped Er:GYSGG crystals.

\begin{tabular}{cccccc}
\hline Crystal & $\begin{array}{c}\text { Wavelength } \\
(\boldsymbol{\mu m})\end{array}$ & $\begin{array}{c}\text { Pumping } \\
\text { Scheme }\end{array}$ & Power/Energy & Efficiency & $\mathbf{M}^{2}$ Factor \\
\hline Er:GYSGG [8] & 2.796 & End & $348 \mathrm{~mW}$ & $9.2 \%$ & 1.94 \\
Er,Pr:GYSGG [9] & 2.79 & End & $284 \mathrm{~mW}$ & $14.8 \%$ & 1.72 \\
GYSGG/Er,Pr:GYSGG [47] & 2.79 & End & $825 \mathrm{~mW}$ & $17 \%$ & 1.7 \\
Er/Pr:GYSGG [48] & 2.79 & Side & $8.86 \mathrm{~W}$ & $7.7 \%{ }^{2}$ & 7.5 \\
Cr,Er,Pr:GYSGG [10] & 2.79 & Side ${ }^{1}$ & $315.8 \mathrm{~mJ}$ & $0.79 \%^{2}$ & - \\
GYSGG/Cr,Er,Pr:GYSGG [49] & 2.79 & Side $^{1}$ & $342.8 \mathrm{~mJ}$ & $0.86 \%{ }^{2}$ & 3.7 \\
Yb,Er,Ho:GYSGG [11] & 2.79 & End & $411 \mathrm{~mW}$ & $11.6 \%$ & 1.97 \\
\hline
\end{tabular}

${ }^{1}$ Lamp pumping. ${ }^{2}$ Electrical-optical conversion efficiency.

\section{Nonlinear Optical Wavelength Extension Based on Nd:GYSGG and Er:GYSGG Lasers}

With the development of growth technology for Nd:GYSGG, its laser performance can now match that of classical garnet laser crystals such as Nd:YAG. A significant advantage of Nd:GYSGG is that it is much easier to realize multi-wavelength operations due to Stark-level splitting, making it possible to generate various wavelengths through further nonlinear optical processes such as OPO, DFG, and stimulated Raman scattering (SRS), extending the wavelength range to the near-, mid-, and far-infrared regions.

Laser light at 1058.4 and $1061.5 \mathrm{~nm}$ produced by a dual-wavelength Nd:GYSGG laser has been used as the fundamental wavelengths to pump noncritically phase-matched intracavity optical parametric oscillators (IOPOs), generating eye-safe lasers in the 1.5-1.6 $\mu \mathrm{m}$ band based on nonlinear crystals KTP and KTA. Using a KTA crystal, two signal wavelengths at 1525.1 and $1531.2 \mathrm{~nm}$ were produced simultaneously [56], with a maximum average output power, single-pulse energy, and peak power of $296 \mathrm{~mW}, 2.96 \mu \mathrm{J}$, and $6.4 \mathrm{~kW}$, respectively. For KTP associated with a specially designed folded cavity for mode-matching and thermal stability, dual-signal operation at 1562.1 and $1567.4 \mathrm{~nm}$ was achieved [57]. The average power, single-pulse energy and peak power increased to $750 \mathrm{~mW}, 75 \mu \mathrm{J}$, and $22.7 \mathrm{~kW}$, respectively. As the OPO wavelengths coincide with the absorption bands of gases such as $\mathrm{C}_{2} \mathrm{H}_{2}, \mathrm{CO}$, and $\mathrm{CO}_{2}$, such dual-wavelength OPOs can be good laser source options in differential absorption lidar (DIAL) for remote gas sensing.

Besides second-order nonlinear devices, third-order nonlinear effects also have been effectively achieved by pumping with an Nd:GYSGG laser. Jiang et al. demonstrated a $1.5 \mu \mathrm{m}$ eye-safe laser via SRS using an $a$-cut $\mathrm{YVO}_{4}-\mathrm{Nd}: \mathrm{YVO}_{4}$ crystal as the nonlinear medium and pumped inside a 1321/1336 nm dual-wavelength Nd:GYSGG laser cavity [58]. A schematic and the output spectrum are shown in Figure 12. In-band pumping at $882.9 \mathrm{~nm}$ was employed to alleviate the serious thermal lensing effect and enhance the eye-safe laser output power. When the absorbed pump power was $23.2 \mathrm{~W}$, a total Stokes output power of $2.11 \mathrm{~W}$ was achieved with a simultaneous dual-wavelength at $1497 \mathrm{~nm}$ and $1516 \mathrm{~nm}$. The pulse repetition rate was $23 \mathrm{kHz}$ and the corresponding conversion efficiency was $9.1 \%$. 


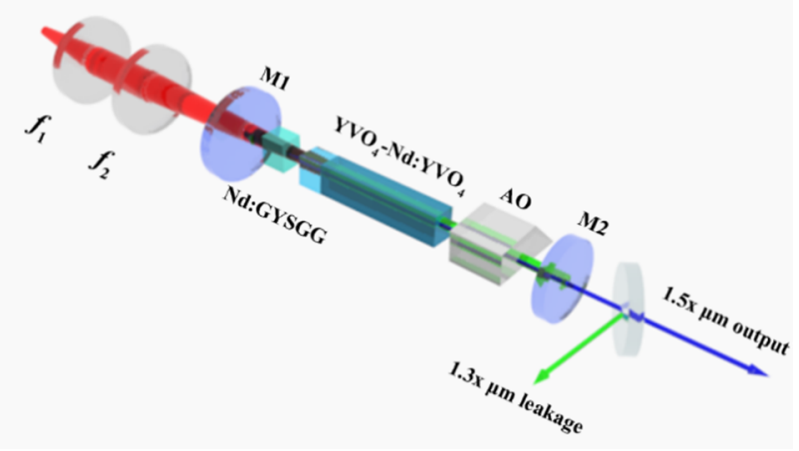

(a)

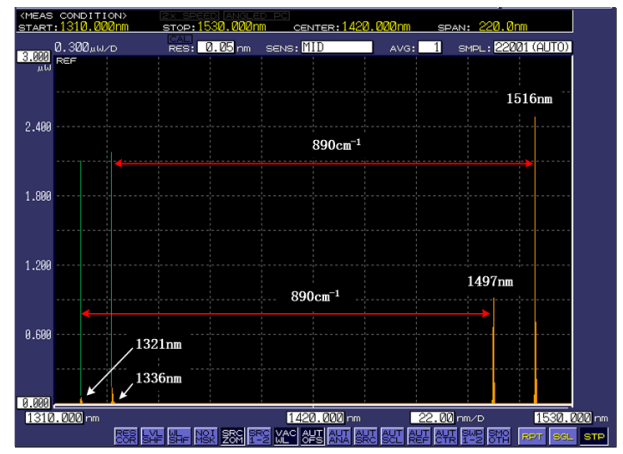

(b)

Figure 12. Schematic of the dual-wavelength $\mathrm{YVO}_{4}$ Raman laser intracavity pumped by an Nd:GYSGG laser (a) and the output fundamental/Stokes spectrum (b) [58].

DFG is an important approach for terahertz-wave generation, in which a dual-wavelength laser plays the main role [59]. Since various simultaneous dual-wavelength laser pulses in Nd:GYSGG such as 1053/1058, 1058/1061, 1321/1336, and 1562/1567 nm, have been realized to provide frequency intervals covering $0.6 \mathrm{THz}$ to $2.5 \mathrm{THz}$, terahertz waves can be extracted using nonlinear crystals, such as GaSe, $\mathrm{ZnGeP}_{2}$, DAST, etc. The prerequisite is that the relative intensity of the two laser lines of the dual-wavelength laser should be sufficiently stable.

Nonlinear frequency conversion based on mid-infrared $\mathrm{Er}^{3+}$-doped GYSGG lasers, which has not yet been achieved, also has great potential for pumping infrared nonlinear crystals to generate 3-5 $\mu \mathrm{m}$ and 8-12 $\mu \mathrm{m}$ mid-infrared lasers. On the one hand, the quantum efficiency is much higher when using $3 \mu \mathrm{m}$ pumping than with pumping around $1.06 \mu \mathrm{m}$. On the other hand, some nonlinear crystals, such as $\mathrm{GaAs}$ and $\mathrm{ZnGeP}_{2}$, are non-transparent in the near-infrared range, and require mid-infrared pumping. Considering the remarkable radiation-resistant characteristics $\mathrm{Of}^{3 r^{3+}}$-doped GYSGG, it is believed that lasers using this material will be popular in nonlinear frequency conversion once the efficiency is improved, especially in high-radiation space applications.

\section{Conclusions}

In conclusion, this paper gives a review of the performances of $\mathrm{Nd}^{3+}$ - and $\mathrm{Er}^{3+}$-doped lasers based on a new but promising host material-GYSGG. The development of Nd:GYSGG lasers delivering wavelengths in the ranges of $0.9,1.06,1.1,1.3$, and $1.4 \mu \mathrm{m}$, and with operation modes covering CW, Q-switching, and mode-locking is elaborated. Some typical applications of Nd:GYSGG lasers are also given, in pumping nonlinear frequency conversion for wavelength extension to longer wavelengths through OPO and SRS. A distinctive feature of these lasers is that simultaneous dual- or multiple-wavelength operation is easily accessible, which is of great interest in applications of precision measurement, spectroscopy, remote sensing, frequency conversion to terahertz, and so on. Er:GYSGG, which can directly give 2.7-3 $\mu \mathrm{m}$ laser radiation, has been proven to be a good mid-infrared laser gain medium for both LD and lamp pumping. To overcome the self-terminating effect in Er:GYSGG, co-doping of $\mathrm{Yb}^{3+}, \mathrm{Cr}^{3+}, \mathrm{Pr}^{3+}, \mathrm{Ho}^{3+}$, etc. was studied as sensitizer and deactivator ions, in which great progress has been made during the past few years. The performances of GYSGG lasers doped with both $\mathrm{Nd}^{3+}$ and $\mathrm{Er}^{3+}$ ions have reached those of the state-of-the-art conventional garnet host materials YAG, GGG, YSGG, etc. Considering that $\mathrm{Nd}^{3+}$ - and $\mathrm{Er}^{3+}$-doped GYSGG crystals possess extraordinary radiation-resistant characteristics compared to Nd/Er:YAG, etc., it is expected that this review will help researchers to learn about such crystals and promote their commercialization and application in the near future.

Funding: This work was funded by the National Natural Science Foundation of China (Grant No. 61675146) and the Natural Science Foundation of Tianjin City (18JCYBJC16700).

Conflicts of Interest: The author declares no conflict of interest. 


\section{References}

1. Kane, T.J.; Byer, R.L. Monolithic, unidirectional single-mode Nd:YAG ring laser. Opt. Lett. 1985, $10,65-67$. [CrossRef]

2. Pfistner, C.; Albers, P.; Weber, H.P.; Ostroumov, V.G.; Zharikov, E.V.; Shcherbakov, I.A.; Lutts, G.B.; Zagumenny, A.I. Spectroscopic and laser characteristics of new YSGG, GSGG, GSAG mixtures doped with $\mathrm{Nd}^{3+}$. Opt. Mater. 1992, 1, 101-110. [CrossRef]

3. Qin, L.J.; Tang, D.Y.; Xie, G.Q.; Dong, C.M.; Jia, Z.T.; Tao, X.T. High-power continuous wave and passively Q-switched laser operations of a Nd:GGG crystal. Laser Phys. Lett. 2008, 5, 100-103. [CrossRef]

4. Koechner, W. Solid-state Laser Engineering, 6th ed.; Springer: New York, NY, USA, 2013.

5. Luo, J.Q. Study on the Growth and Properties of New-Type Antiradiation Nd:GYSGG Crystal and Up-Conversion Performance of Er,Yb:GSGG and Er:GSGG. Ph.D. Thesis, Chinese Academy of Sciences, Beijing, China, 2009.

6. Ding, S.; Zhang, Q.; Luo, J.; Liu, W.; Sun, D.; Wang, X.; Sun, G.; Gao, J. Basic Properties of Nd-Doped GYSGG Laser Crystal. Cryst. Res. Technol. 2017, 52, 1700132. [CrossRef]

7. Gao, J.; Zhang, Q.; Sun, D.; Luo, J.; Liu, W.; Yin, S. Energy levels fitting and crystal-field calculations of $\mathrm{Nd}^{3+}$ doped in GYSGG crystal. Opt. Commun. 2012, 285, 4420-4426. [CrossRef]

8. Chen, J.; Sun, D.; Luo, J.; Xiao, J.; Dou, R.; Zhang, Q. Er ${ }^{3+}$ doped GYSGG crystal as a new laser material resistant to ionizing radiation. Opt. Commun. 2013, 301-302, 84-87. [CrossRef]

9. Chen, J.; Sun, D.; Luo, J.; Zhang, H.; Dou, R.; Xiao, J.; Zhang, Q.; Yin, S. Spectroscopic properties and diode end-pumped $2.79 \mu \mathrm{m}$ laser performance of Er,Pr:GYSGG crystal. Opt. Express 2013, 21, 23425-23432. [CrossRef]

10. Luo, J.; Sun, D.; Zhang, H.; Guo, Q.; Fang, Z.; Zhao, X.; Cheng, M.; Zhang, Q.; Yin, S. Growth, spectroscopy, and laser performance of a $2.79 \mu \mathrm{m} \mathrm{Cr,Er,Pr:GYSGG} \mathrm{radiation-resistant} \mathrm{crystal.} \mathrm{Opt.} \mathrm{Lett.} \mathrm{2015,} \mathrm{40,} \mathrm{4194-4197.}$ [CrossRef]

11. Chen, J.; Sun, D.; Luo, J.; Xiao, J.; Kang, H.; Zhang, H.; Cheng, M.; Zhang, Q.; Yin, S. Spectroscopic, diode-pumped laser properties and gamma irradiation effect on Yb,Er,Ho:GYSGG crystals. Opt. Lett. 2013, 38, 1218-1220. [CrossRef] [PubMed]

12. Krupke, W.F.; Shinn, M.D.; Marion, J.E.; Caird, J.A.; Stokowski, S.E. Spectroscopic, optical, and thermomechanical properties of neodymium- and chromium-doped gadolinium scandium gallium garnet. J. Opt. Soc. Am. B 1986, 3, 102-114. [CrossRef]

13. Rapaport, A.; Zhao, S.; Xiao, G.; Howard, A.; Bass, M. Temperature dependence of the 1.06- $\mu \mathrm{m}$ stimulated emission cross section of neodymium in YAG and in GSGG. Appl. Opt. 2002, 41, 7052-7057. [CrossRef]

14. Sun, C.L.; Zhong, K.; Zhang, C.G.; Yao, J.Q.; Xu, D.G.; Zhang, F.; Pei, Y.Q.; Zhang, Q.L.; Luo, J.Q.; Sun, D.L.; Yin, S.T. Stimulated emission cross section of the ${ }^{4} \mathrm{~F}_{3 / 2} \rightarrow{ }^{4} \mathrm{I}_{11 / 2}$ transition of Nd:GYSGG. Laser Phys. Lett. 2012, 9, 410-414. [CrossRef]

15. Zhong, K.; Yao, J.; Sun, C.; Zhang, C.; Miao, Y.; Wang, R.; Xu, D.; Zhang, F.; Zhang, Q.; Sun, D.; Yin, S. Efficient diode-end-pumped dual-wavelength Nd, Gd:YSGG laser. Opt. Lett. 2011, 36, 3813-3815. [CrossRef] [PubMed]

16. Zhang, B.; Xu, J.; Wang, G.; He, J.; Wang, W.; Zhang, Q.; Sun, D.; Luo, J.; Yin, S. Continuous-wave and passively Q-switched laser performance of a disordered Nd:GYSGG crystal. Opt. Commun. 2011, 284, 5734-5737. [CrossRef]

17. Song, Q.; Wang, G.; Zhang, B.; Wang, W.; Wang, M.; Zhang, Q.; Sun, G.; Bo, Y.; Peng, Q. Diode-pumped passively dual-wavelength Q-switched Nd:GYSGG laser using graphene oxide as the saturable absorber. Appl. Opt. 2015, 54, 2688-2692. [CrossRef]

18. Gao, Y.J.; Zhang, B.Y.; Song, Q.; Wang, G.J.; Wang, W.J.; Hong, M.H.; Dou, R.Q.; Sun, D.L.; Zhang, Q.L. Dual-wavelength passively Q-switched Nd:GYSGG laser by tungsten disulfide saturable absorber. Appl. Opt. 2016, 55, 4929-4932. [CrossRef] [PubMed]

19. Song, Q.; Zhang, B.Y.; Wang, G.J. Characterization of $\mathrm{SnSe}_{2}$ saturable absorber by $\mathrm{THz}-\mathrm{TDS}$ and used in dual-wavelength passively Q-switched laser. Optik 2018, 174, 35-39. [CrossRef]

20. Ma, B.; Li, P.; Chen, X.; Wang, L.; Liu, B.; Song, T. Gold nano-triangles as saturable absorbers for a dual-wavelength passively Q-switched Nd:GYSGG laser. Laser Phys. 2018, 28, 075802. [CrossRef] 
21. Song, Q.; Wu, Z.; Ma, P.; Wang, G.; Zhang, B. $\mathrm{TiS}_{2}, \mathrm{MoS}_{2}, \mathrm{WS}_{2} / \mathrm{Sb}_{2} \mathrm{Te}_{3}$ mixed nanosheets saturable absorber for dual-wavelength passively Q-switched Nd:GYSGG Laser. Infrared Phys. Technol. 2018, 92, 1-5. [CrossRef]

22. Song, Q.; Wang, G.; Zhang, B.; Zhang, Q.; Wang, W.; Wang, M.; Sun, G.; Bo, Y.; Peng, Q. Dual-wavelength self-Q-switched Nd:GYSGG laser. J. Mod. Opt. 2015, 62, 1655-1659. [CrossRef]

23. Zhang, B.Y.; Xu, J.L.; Wang, G.J.; He, J.L.; Wang, W.J.; Zhang, Q.L.; Sun, D.L.; Luo, J.Q.; Yin, S.T. Diode-pumped passively mode-locked Nd:GYSGG laser. Laser Phys. Lett. 2011, 8, 787-790. [CrossRef]

24. Song, Q.; Wang, G.; Zhang, B.; Zhang, Q.; Wang, W.; Wang, M.; Sun, G.; Bo, Y.; Peng, Q. Passively Q-switched mode-locked dual-wavelength Nd:GYSGG laser using graphene oxide saturable absorber. Opt. Commun. 2015, 347, 64-67. [CrossRef]

25. Zhong, K.; Sun, C.; Yao, J.; Xu, D.; Xie, X.; Cao, X.; Zhang, Q.; Luo, J.; Sun, D.; Yin, S. Efficient continuous-wave 1053-nm Nd:GYSGG laser with passively Q-switched dual-wavelength operation for terahertz generation. IEEE J. Quantum Electron. 2013, 49, 375-379. [CrossRef]

26. Shen, B.J.; Kang, H.X.; Zhang, C.G.; Zhang, Q.L.; Sun, D.L.; Yin, S.T.; Luo, J.Q.; Chen, P.; Gao, R.L.; Liang, J.; Gao, H.J. A diode-end-pumped Nd:GYSGG continuous wave laser at 1104 nm. Laser Phys. 2013, 23, 035805. [CrossRef]

27. Lin, H.; Liu, H.; Huang, X.; Copner, N.; Sun, D. Continuous-wave Nd:GYSGG laser at $1.1 \mu$ m. J. Mod. Opt. 2018, 65, 423-426. [CrossRef]

28. Wagner, W.G.; Lengyel, B.A. Evolution of the giant pulse in a laser. J. Appl. Phys. 1963, 34, $2040-2046$. [CrossRef]

29. Degnan, J.J. Theory of the optimally coupled Q-switched laser. IEEE J. Quantum Electron. 1989, 25, $214-220$. [CrossRef]

30. Dun, Y.; Feng, C.; Chen, X.; Li, P.; Wang, Q.; Song, T. Gold nanorods based passively Q-switched solid-state laser at $1111.4 \mathrm{~nm}$ wavelength. Optik 2017, 147, 360-365. [CrossRef]

31. Zhong, K.; Sun, C.L.; Yao, J.Q.; Xu, D.G.; Pei, Y.Q.; Zhang, Q.L.; Luo, J.Q.; Sun, D.L.; Yin, S.T. Continuous-wave Nd:GYSGG laser around $1.3 \mu \mathrm{m}$. Laser Phys. Lett. 2012, 9, 491-495. [CrossRef]

32. Zhong, K.; Xu, W.Z.; Sun, C.L.; Yao, J.Q.; Xu, D.G.; Cao, X.L.; Zhang, Q.L.; Luo, J.Q.; Sun, D.L.; Yin, S.T. Continuous-wave Nd:GYSGG laser properties in 1.3 and $1.4 \mu \mathrm{m}$ regions based on ${ }^{4} \mathrm{~F}_{3 / 2}$ to ${ }^{4} \mathrm{I}_{13 / 2}$ transition. J. Phys. D Appl. Phys. 2013, 46, 315106. [CrossRef]

33. Song, T.; Li, P.; Chen, X.; Ma, B.; Dun, Y. Passively Q-switched Nd:GYSGG laser operating at $1.3 \mu \mathrm{m}$ with V:YAG as saturable absorber. Optik 2016, 127, 10621-10625. [CrossRef]

34. Lin, H.Y.; Sun, D.; Copner, N.; Zhu, W.Z. Nd:GYSGG laser at $1331.6 \mathrm{~nm}$ passively Q-switched by a Co: $\mathrm{MgAl}_{2} \mathrm{O}_{4}$ crystal. Opt. Mater. 2017, 69, 250-253. [CrossRef]

35. Li, H.; Wang, Z.M.; Zhang, F.F.; Wang, M.Q.; Li, J.J.; Mao, Y.L.; Yuan, L.; Zong, N.; Zhang, S.J.; Yang, F.; Bo, Y.; Gao, C.Q.; Cui, D.F.; Peng, Q.J.; Xu, Z.Y. Sub-pm linewidth nanosecond Nd:GYSGG laser at $1336.6 \mathrm{~nm}$. Opt. Lett. 2015, 40, 776-779. [CrossRef] [PubMed]

36. Sun, C.; Zhong, K.; Yao, J.; Xu, D.; Cao, X.; Zhang, Q.; Luo, J.; Sun, D.; Yin, S. Diode-pumped continuous-wave quasi-three-level Nd:GYSGG laser at $937 \mathrm{~nm}$. Opt. Commun. 2013, 294, 229-232. [CrossRef]

37. Zhou, R.; Zhang, T.L.; Li, E.; Ding, X.; Cai, Z.; Zhang, B.; Wen, W.; Wang, P.; Yao, J. 8.3 W diode-end-pumped continuous-wave Nd:YAG laser operating at 946-nm. Opt. Express 2005, 13, 10115-10119. [CrossRef]

38. Chi, H.; Baumgarten, C.M.; Jankowska, E.; Dehne, K.A.; Murray, G.; Meadows, A.R.; Berrill, M.; Reagan, B.A.; Rocca, J.J. Thermal behavior characterization of a kilowatt-power-level cryogenically cooled Yb:YAG active mirror laser amplifier. J. Opt. Soc. Am. B 2019, 36, 1084-1090. [CrossRef]

39. Ganija, M.; Hemming, A.; Simakov, N.; Boyd, K.; Haub, J.; Veitch, P.; Munch, J. High power cryogenic Ho:YAG laser. Opt. Express 2017, 25, 31889-31895. [CrossRef]

40. Cho, C.Y.; Lee, C.Y.; Chang, C.C.; Tuan, P.H.; Huang, K.F.; Chen, Y.F. 24-W cryogenically cooled Nd:YAG monolithic 946-nm laser with a slope efficiency $>70 \%$. Opt. Express 2015, 23, 10126-10131. [CrossRef]

41. Cho, C.Y.; Huang, T.L.; Cheng, H.P.; Huang, K.F.; Chen, Y.F. Exploring the power scaling of the cryogenic $946 \mathrm{~nm}$ monolithic laser. Laser Phys. Lett. 2018, 15, 085801. [CrossRef]

42. Zhong, K.; Liu, C.; Liu, Y.; Mei, J.; Shi, J.; Xu, D.; Yao, J. Power-ratio tunable dual-band Nd:GYSGG laser at $0.94 \mu \mathrm{m}$ and $1.06 \mu \mathrm{m}$. Laser Phys. 2017, 27, 125804. [CrossRef]

43. Yao, J.Q.; Xu, D.G. All Solid State Laser and Nonlinear Optical Frequency Conversion Technology; Science Press: Beijing, China, 2007. 
44. Wang, Y.G.; Ma, X.Y.; Li, C.Y.; Zhang, Z.G.; Zhang, B.Y.; Zhang, Z.G. A passively mode-locked diode-end-pumped Nd:YAG laser with a semiconductor saturable absorber mirror grown by metal organic chemical vapour deposition. Chin. Phys. Lett. 2003, 20, 1960-1962.

45. Li, T.; Zhao, S.; Zhuo, Z.; Wang, Y. Thermal effects investigation and cavity design in passively mode-locked $\mathrm{Nd}: \mathrm{YVO}_{4}$ laser with a SESAM. Opt. Commun. 2009, 282, 940-943. [CrossRef]

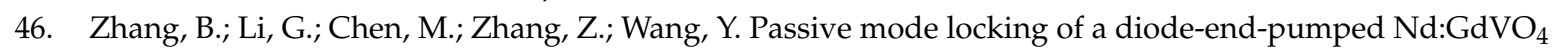
laser with a semiconductor saturable absorber mirror. Opt. Lett. 2003, 28, 1829-1831. [CrossRef]

47. Chen, J.; Sun, D.; Luo, J.; Zhang, H.; Cao, S.; Xiao, J.; Kang, H.; Zhang, Q.; Yin, S. Performances of a diode end-pumped GYSGG/Er,Pr:GYSGG composite laser crystal operated at $2.79 \mu \mathrm{m}$. Opt. Express 2014, 22, 23795-23800. [CrossRef]

48. Zhao, X.; Sun, D.; Luo, J.; Zhang, H.; Fang, Z.; Quan, C.; Hu, L.; Cheng, M.; Zhang, Q.; Yin, S. Laser performance of a $966 \mathrm{~nm}$ LD side-pumped Er,Pr:GYSGG laser crystal operated at $2.79 \mu \mathrm{m}$. Opt. Lett. 2018, 43, 4312-4315. [CrossRef]

49. Fang, Z.; Sun, D.; Luo, J.; Zhang, H.; Zhao, X.; Quan, C.; Hu, L.; Cheng, M.; Zhang, Q.; Yin, S. Thermal analysis and laser performance of a GYSGG/Cr,Er,Pr:GYSGG composite laser crystal operated at $2.79 \mu \mathrm{m}$. Opt. Express 2017, 25, 21349-21357. [CrossRef]

50. Rabinovich, W.S.; Bowman, S.R.; Feldman, B.J.; Winings, M.J. Tunable laser pumped $3 \mu \mathrm{m} \mathrm{Ho} \mathrm{YAlO}_{3}$ laser. IEEE J. Quantum Electron. 1991, 27, 895-897. [CrossRef]

51. Zhang, H.; Sun, D.; Luo, J.; Peng, F.; Fang, Z.; Zhao, X.; Quan, C.; Cheng, M.; Zhang, Q.; Yin, S. Growth, spectroscopy, and laser performance of a radiation-resistant $\mathrm{Cr}, \mathrm{Yb}, \mathrm{Ho}, \mathrm{Pr}: G Y S G G$ crystal for $2.84 \mu \mathrm{m}$ mid-infrared laser. J. Lumin. 2018, 194, 636-640. [CrossRef]

52. Messner, M.; Heinrich, A.; Hagen, C.; Unterrainer, K. High brightness diode pumped Er:YAG laser system at $2.94 \mu \mathrm{m}$ with nearly $1 \mathrm{~kW}$ peak power. Proc. SPIE 2016, 9726, 972602.

53. Messer, M.; Heinrich, A.; Unterrainer, K. High-energy diode side-pumped Er:LiYF 4 laser. Appl. Opt. 2018, 57, 1497-1503. [CrossRef]

54. Wang, L.; Wang, J.; Yang, J.; Wu, X.; Sun, D.; Yin, S.; Jiang, H.; Wang, J.; Xu, C. 2.79 um high peak power LGS electro-optically Q-switched Cr,Er:YSGG laser. Opt. Lett. 2013, 38, 2150-2152. [CrossRef]

55. Sanamyan, T. Efficient cryogenic mid-IR and eye-safe Er:YAG laser. J. Opt. Soc. Am. B 2016, 33, D1-D6. [CrossRef]

56. Zhong, K.; Guo, S.; Wang, M.; Mei, J.; Xu, D.; Yao, J. A non-critically phase matched KTA optical parametric oscillator intracavity pumped by an actively Q-switched Nd:GYSGG laser with dual signal wavelengths. Opt. Commun. 2015, 344, 17-20. [CrossRef]

57. Wang, M.; Zhong, K.; Mei, J.; Guo, S.; Xu, D.; Yao, J. Simultaneous dual-wavelength eye-safe KTP OPO intracavity pumped by a Nd:GYSGG laser. J. Phys. D Appl. Phys. 2016, 49, 065101. [CrossRef]

58. Jiang, P.B.; Sheng, Q.; Ding, X.; Sun, B.; Liu, J.; Zhao, C.; Zhang, G.Z.; Yu, X.Y.; Li, B.; Wu, L.; Yao, J.Q. Dual-wavelength eye-safe Nd:GYSGG/YVO 4 intracavity Raman laser under in-band pumping. Opt. Commun. 2017, 383, 6-10. [CrossRef]

59. Zhong, K.; Shi, W.; Xu, D.; Liu, P.; Wang, Y.; Mei, J.; Yan, C.; Fu, S.; Yao, J. Optically pumped terahertz sources. Sci. China Technol. Sci. 2017, 60, 1801-1818. [CrossRef]

(C) 2019 by the author. Licensee MDPI, Basel, Switzerland. This article is an open access article distributed under the terms and conditions of the Creative Commons Attribution (CC BY) license (http://creativecommons.org/licenses/by/4.0/). 